\title{
Questionnaire and Analysis of Microwave Technology Course for College Students
}

\author{
Cheng-Guang SUN ${ }^{1, a, *}$ \\ ${ }^{1}$ Institute of Antenna and Microwave Techniques, Tianjin University of Technology and \\ Education, Tianjin, China \\ asunchengguang_23@163.com \\ ${ }^{*}$ Corresponding author
}

Keywords: Microwave technology, Questionnaire, Analysis.

\begin{abstract}
Study of teaching effect for microwave technology course is developed in this paper. To receive the learning attitude of this course, a questionnaire is designed and tested for college students major in electronic information science and technology. According to answers of the questionnaire, corresponding analyses are carried out. Based on the research of students' thoughts, the teaching approaches will be improved to enhance the interest in learning.
\end{abstract}

\section{Introduction}

For the undergraduates major in electronic information science and technology, microwave technology is a core course of training plan [1]. This curriculum is also a fundamental reference for the graduate students and researchers. It includes electromagnetic theory, transmission lines and waveguides, microwave network analysis, and et al. These contents are not easy to learn, because it requires a solid foundation of mathematics and physics. To understand these contents well, one need to read some books and know some softwares related to this course. In recent years, the course of college students is numerous, and some undergraduates do not know how to study these important courses efficiently. Such problems restrict their interest in learning.

The learning psychology of students is important in teaching process. During author's further education in University of Electronic Science and Technology of China, a questionnaire is designed to test the mindset and intention of the students. The corresponding analyses of the results are provided, and some suggestions are presented.

\section{Results and Analyses of the Questionnaire}

According some reported results in teaching reference [2,3], a questionnaire is carried out for the college students who take the microwave technology as a major course. The sample composes of forty-five undergraduates majoring in electronic information science and technology. In this questionnaire, they will answer fifteen questions in five levels with their intentions. The questions are described in Likert scales: strongly agree (SA), agree (A), neither agree nor disagree (NAD), disagree (D) and strongly disagree (SD) [3,4]. The replies to questions indicate that most students enjoy their major and are not averse to learning this course. However, they do not know how to understand the content in depth by studying related knowledge or engineering software. Several typical questions of the questionnaire are shown in Table 1. The results of these responses are analyzed as below: 
Table 1 Typical questions of the questionnaire

\begin{tabular}{|c|l|}
\hline Number & \multicolumn{1}{c|}{ Explain } \\
\hline Question 1 & Like the discipline of electronic science and technology \\
\hline Question 5 & Like to learn microwave technology, and like to design practical circuits \\
\hline Question 12 & $\begin{array}{l}\text { Have some research experience, familiar with microwave active and passive } \\
\text { circuits, antenna and other basic knowledge }\end{array}$ \\
\hline Question 13 & Participate in online professional BBS discussion \\
\hline Question 14 & Like simulation or programming, familiar with HFSS, ADS, and MATLAB \\
\hline
\end{tabular}

The answers of question 1 are described in Fig. 1. From this figure, the percent of graduates who select the SA, A, and NAD are $20 \%, 44 \%, 27 \%$, respectively. Meanwhile, the percent of averse opinions is only $9 \%$. Therefore, most of the students like or not disgusted with their major. They also interest in learning the main courses of this discipline. As college teachers, we should introduce some new concept and development of the specialty when we teaching the contents of this course. It should enhance the learning initiative of the students and prompt them to find the effective solutions of some problems encountered.

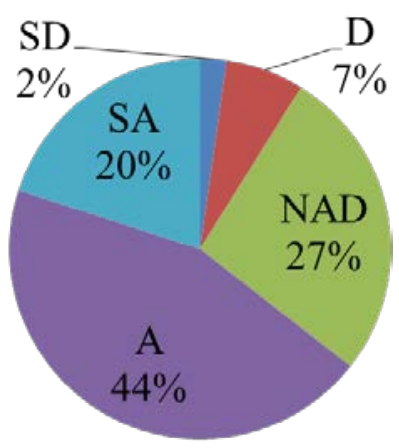

Fig. 1 The percent distribution of answers to question 1.

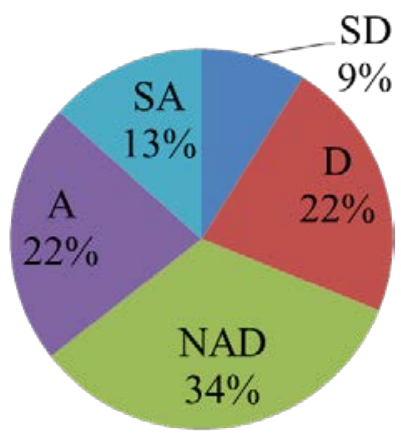

Fig. 2 The percent distribution of answers to question 5.

As shown in Fig. 2, the result of question 5 is illuminated as a pie chart. Students who choose SA or A is $35 \%$ and almost the same as $31 \%$ ones who choose SD or D. Moreover, $34 \%$ of students choose NAD. It is shown that a majority of students are not very interest in comprehending microwave technologies and designing practical microwave circuits. That is because students do not clearly understand the use of textbook knowledge. According to this 
result, the practical application of microwave techniques and some engineering project related to microwave circuits and systems should be introduced in class. These extra contents can improve the motivation of studying.

The percent distribution of answers to question 12 is presented in Fig. 3. From this figure, only $11 \%$ students answer in SA or A scales. The undergraduates have less opportunity to participate in scientific research. While teaching this course, the teacher can come up with some simple scientific research topics by themselves. Students will try their best to work with the research, and are encouraged to learn microwave technology well simultaneously. It is a kind of method to enhance the teaching effect.

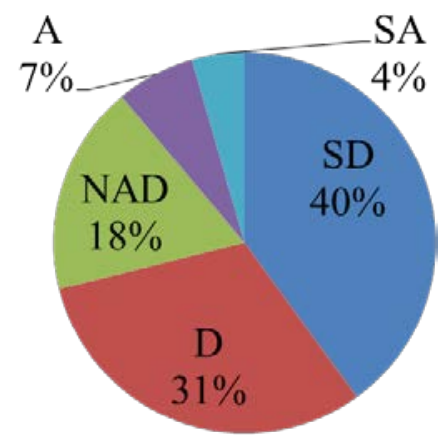

Fig. 3 The percent distribution of answers to question 12.

As described in Fig. 4, the result of question 13 is explained in percent distribution. Nearly $90 \%$ of students have not the experience to participate in the online BBS. They have no motive to discuss professional problems with others, and the network resource is not used effectively. Many experienced technician always join in BBS to share the engineering skills with researchers and students. Consequently, teachers should lead the students to communicate with online experienced engineers actively. It can broaden their knowledge and prompt them to learn this course energetically.

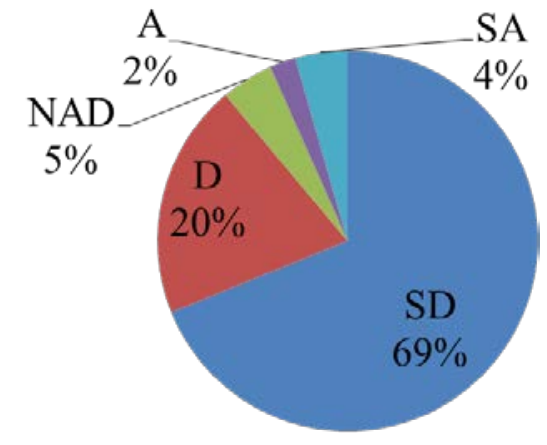

Fig. 4 The percent distribution of answers to question 13

The percent distribution of answers to question 14 is shown in Fig. 5. Students choose SD, D or NAD is $78 \%$. They are not familiar with microwave simulation and programming software. From this pie chart, only $22 \%$ students can use these auxiliary tools. It is because the period related to simulation or programming of this course is limited. Most of students do not know the software and computer language in microwave field. Therefore, more practices refer to 
simulation and programming should be instead of the problems after each chapter. This kind of homework can foster students' interest in learning this course.

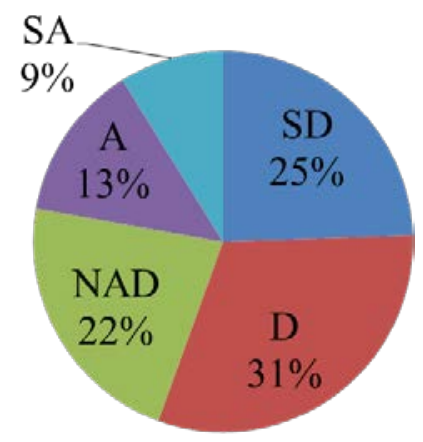

Fig. 5 The percent distribution of answers to question 14

\section{Conclusion}

To improve the teaching effect, a questionnaire is carried out in college students studying microwave technology course. Based on the results and analyses of typical questions, some teaching approaches are discussed. Teacher should add more practical training related to this course in class. If the teaching content is more closely integrated with actual engineering, students will be more focused on this course and work hard for their subject.

\section{References}

[1] D. M. Pozar, Microwave Engineering, third ed., John Wiley \& Sons, Inc., New York, 2005.

[2] J. Duan, L. Qin, B. Zhang, Undergraduate teaching reform of microwave technology, Education Teaching Forum, 5(2017) 135-136, (in Chinese).

[3] Q. Li, H. Xiong, Q. Gao, T. Wang, The questionnaire for a digital circuit course, Journal of Electrical \& Electronic Education, 32.4(2010) 13-15, 21, (in Chinese).

[4] Information on http://www.socialresearchmethods.net/kb/scallik.php. 